\title{
EIח反A
}

Revista Eletrônica de Estudos Integrados em Discurso e Argumentação

\section{DIRECIONAMENTO ARGUMENTATIVO EM NOTÍCIAS ON-LINE}

\author{
Lívia Letícia Zanier Gomes ${ }^{\mathrm{i}}$ \\ Bárbara Helena Rabeloii
}

Resumo: Este artigo assume a imparcialidade no gênero textual notícia como mito e objetiva averiguar como acontece a tomada de posição do seu locutor no meio eletrônico e como esse posicionamento pode direcionar o hiperleitor a conclusões. Com um corpus formado por notícias veiculadas em jornais on-line brasileiros, verificou-se como ocorre o direcionamento para uma dada conclusão ou perspectiva. A pesquisa concentrou-se em verificar se esse direcionamento ocorre por meio dos elementos constitutivos do gênero ou se ocorre por meio dos hiperlinks sugeridos. Tem como referenciais teóricos pressupostos da Semântica Argumentativa com teorias como a Teoria dos Blocos Semânticos de Carrel e Ducrot (1992), além do apontamento para diversos outros recursos argumentativos intrínsecos à língua. Foi verificado que a isenção argumentativa do gênero "notícia" veiculado em jornais online é apenas um simulacro e que, além do corpo da notícia, os hiperlinks apresentados contribuem para direções argumentativas apontadas pelo locutor do texto.

Palavras-chave: Notícia on-line. Hiperlinks. Orientação argumentativa. Argumentação.

\begin{abstract}
This paper assumes impartiality in the news genre as a myth and its goal is to examine how the speaker assumes a stance in the digital media and how this position can lead the hyper-reader to some conclusion. The analysis of the corpus, constituted by news published in Brazilian online newspapers, revealed how this process unfolds. The research focused on verifying whether such guidance occurs through the constituent elements of the genre or through the suggested hyperlinks. The theoretical framework derives from Argumentative Semantics studies, such as the Theory of Semantic Blocks by Carrel and Ducrot (1992), besides several other argumentative resources intrinsic to language. It was possible to find that the argumentative exemption of the news genre in online newspapers is just a simulation and that, alongside the news itself, the hyperlinks contribute to argumentative directions indicated by the text speaker.
\end{abstract}

Keywords: Online News. Hyperlinks. Argumentative orientation. Argumentation.

i Mestre e Doutoranda em Estudos Linguísticos pela Universidade Federal de Uberlândia (UFU). Docente do Instituto Federal do Triângulo Mineiro (IFTM), Campus Uberaba, Parque Tecnológico. E-mail: liviazanier@gmail.com.

ii Mestranda em Estudos Linguísticos pela Universidade Federal de Uberlândia (UFU). Docente da Sociedade Educacional de Patrocínio. E-mail: barbarahrabelo@yahoo.com.br 
EID\&A - Revista Eletrônica de Estudos Integrados em Discurso e Argumentação, Ilhéus, n. 11, jan/jun.2016.

\section{Introdução}

A semântica argumentativa é a área de estudos que nos permite evidenciar mecanismos inúmeros de argumentação na língua. Por argumentação, compreendemos a utilização de recursos linguísticos com fins a orientar o interlocutor a uma direção (conclusão) desejada. Por compreendermos que não existe neutralidade discursiva e que a toda interação subjaz uma intenção, entendemos que a argumentatividade é intrínseca à língua e que toda interação possui uma direção argumentativa.

De acordo com Fiorin \& Savioli (1996, p. 285), "argumentar é agir sobre o outro". Assim, em todo ato de comunicação é possível perceber a intenção de realizar uma ação sobre o outro, por meio de um "fazer crer e um fazer fazer" (FIORIN; SAVIOLI, 1996, p. 285). A argumentação, dessa forma, está presente em toda interação comunicativa e tem esse propósito. Nesse sentido, portanto, não há texto imparcial ou neutro, visto que todo texto tem uma orientação argumentativa e pretende "conduzir o destinatário em tal ou qual direção" (DUCROT, 1981, p. 178).

Partindo da assunção de que não há neutralidade discursiva, trazemos como foco deste trabalho a análise de um gênero textual muitas vezes concebido como gênero "neutro", como gênero que porta "verdades", "fatos objetivos" a fim de levar o leitor à "sua própria conclusão" frente a eles: o gênero notícia. É o que vemos na presente definição de Ramos (1970, p. 171) de que a notícia:

[...] limita-se à narração do fato, sem nenhuma análise, interpretação, comentário ou pormenor dispensável. [...] A notícia pode veicular opinião ou apreciação de pessoas que participaram do fato, mas sempre entre aspas.

Por acreditarmos que a argumentação é intrínseca à língua, não aderimos à ideia de que a notícia consiga ser uma apresentação (neutra) de fatos. Corroboramos as ideias de Mosca (1999, p.26) de que "o ato de informar não existe em estado puro e serve antes a convencer e persuadir do que por si próprio". Com isso, trazemos a este artigo a ideia de que as notícias não são imparciais (derrubando o que consideramos ser um "mito da neutralidade discursiva") e de que elas direcionam (argumentativamente) o leitor.

Assim é que discursos que se têm como informativos, tais como o científico e o jornalístico, são o exemplo disso, uma vez que existem em função de determinada finalidade prática a ser atingida. Por essa questão, coloca-se em 
EID\&A - Revista Eletrônica de Estudos Integrados em Discurso e Argumentação, llhéus, n. 11, jan/jun.2016.

questão a tradicional divisão das modalidades dos gêneros jornalísticos em informativos, interpretativos e opinativos que, na realidade, serve apenas para balizar a práxis jornalística, quando não mesmo para despistar um leitor desavisado (MOSCA, 1999, p. 26).

Nesse sentido, a definição de uma manchete, os termos utilizados e o ângulo escolhido de uma fotografia para ilustração carregam em si posicionamentos argumentativos, pois são o resultado de julgamento e de decisões sobre o que vai ser noticiado. Se essa visão já pode ser percebida nas notícias veiculadas em jornais impressos, estendemos nosso trabalho aos jornais eletrônicos, para as notícias on-line, por partirmos do pressuposto de que, por se tratarem de hipertextos e trazerem hiperlinks, as notícias on-line trazem recursos diferentes para direcionar o leitor para o ponto de vista que se quer enunciar.

Escolhemos, aqui, um recorte de análise de notícias circulantes em meio eletrônico, trazendo as seguintes perguntas às quais procuraremos responder: (1) como o direcionamento nas notícias eletrônicas para uma conclusão ou perspectiva se faz? (2) Que contribuições o texto da notícia traz para o direcionamento? (3) Os hiperlinks, característicos desse gênero no meio eletrônico, contribuem no direcionamento argumentativo? (4) O direcionamento se confirma no texto base e/ou nos hiperlinks sugeridos? Para isso, realizamos o seguinte percurso metodológico: escolhemos dois "fatos jornalísticos" que foram veiculados no mesmo dia em forma de notícia em três jornais on-line diferentes, sendo eles: $\mathrm{IG}^{1}$, $\mathrm{UOL}^{2}$, Estadão ${ }^{3}$. Os dois fatos que elencamos foram: a greve nas universidades federais e a aprovação da redução da maioridade penal. A seguir, passamos à análise dos elementos constitutivos do gênero, bem como dos hiperlinks sugeridos, embasando-nos em teorias da semântica argumentativa, como a teoria dos blocos semânticos e outros princípios propostos como intrínsecos à língua.

Este artigo apresenta-se dividido nas seguintes seções: (i) introdução; (ii) o mito da neutralidade no discurso jornalístico; (iii) os procedimentos metodológicos; (iv) análise; (v) considerações finais.

\footnotetext{
${ }^{1}$ Disponível em: http://ultimosegundo.ig.com.br/ Acesso em: 01 jul.2015

2 Disponível em: http://noticias.uol.com.br/ Acesso em: 01 jul.2015

3 Disponível em: http://www.estadao.com.br/ Acesso em: 01 jul.2015
} 
EID\&A - Revista Eletrônica de Estudos Integrados em Discurso e Argumentação, Ilhéus, n. 11, jan/jun.2016.

10 mito da neutralidade no discurso jornalístico

É geralmente sob a denominação "objetividade" que se constrói o discurso jornalístico. Como exemplo, o Manual de Redação e Estilo de $O$ Estado de São Paulo, em sua terceira edição, traz a seguinte orientação: "Seja claro, preciso, direto, objetivo e conciso" (MARTINS, 1997, p. 15, grifos do autor). Em seguida, adiciona: "Faça textos imparciais e objetivos. Não exponha opiniões, mas fatos, para que o leitor tire deles as próprias conclusões" (Ibid., p. 17, grifos do autor).

Rossi e Ramires (2013), em artigo em que discutem a imparcialidade como qualidade jornalística, apontam que

\begin{abstract}
A condição de isento, imparcial, garante ao jornalista e ao seu trabalho uma espécie de selo de garantia do produto notícia. Uma das primeiras explicações para significar o jornalismo: a Teoria do Espelho, inspirada no positivismo do filósofo francês Auguste Comte (1798-1857) apontava que a notícia seria de qualidade se o jornalista conseguisse retratar fielmente o fato como se houvesse uma imagem a ser refletida da notícia e que pudesse ser captada pelo profissional e assim transcrita (Ibid., p. 78).
\end{abstract}

Os autores mencionam também que, com o desenvolvimento dos estudos de comunicação e jornalismo, a Teoria do Espelho foi duramente atacada; porém, afirmam que a classe jornalística, além do senso comum, ainda tende a se apoiar na fidedignidade de reprodução dos fatos ao explicarem os procedimentos jornalísticos.

Para Barbosa (2008),

O formato estandardizado da notícia visando à objetividade é, portanto, multifuncional: dá o aval para uma reportagem ser publicada, já que mostra os dois lados da questão, mesmo não sendo crítica ou analítica; protege o repórter da acusação de ser partidário de alguma causa, e transfere a responsabilidade da tomada de posição para os entrevistados e o público-leitor (Ibid., p. 53).

Nos textos que analisamos para este trabalho, percebemos a rotineira inserção, por parte do repórter, de diversos lados da questão nos textos das notícias, isto é, percebemos a inserção de mais de um ponto de vista, na tentativa de mesclar no texto pontos de vista de muitos dos envolvidos no fato noticiado.

Conforme Fiorin (2015, p. 83), "a objetividade, a neutralidade e a imparcialidade são impossíveis, pois a linguagem está sempre carregada de pontos de vista". Segundo esse mesmo autor, o que não pode ocorrer em notícias jornalísticas é que os fatos sejam forjados. Para manter o equilíbrio, os 
EID\&A - Revista Eletrônica de Estudos Integrados em Discurso e Argumentação, Ilhéus, n. 11, jan/jun.2016.

jornais procuram apresentar pontos de vista distintos. Essa apresentação de enunciadores diversos ocorre tanto nas notícias jornalísticas impressas quanto nas eletrônicas.

Cabe salientar que ocorre, no meio jornalístico, a distinção entre imprensa séria e imprensa sensacionalista. Segundo Fiorin (2015),

Na dita imprensa séria, a diagramação é equilibrada; [...] os textos e as fotos apresentam uma distribuição simétrica [...]. Com o apagamento das marcas da enunciação no enunciado, cria-se um efeito de sentido de objetividade e distanciamento. Com o apagamento da enunciação, é como se as notícias se enunciassem a si mesmas, o que gera um efeito de sentido de verdade. Com o uso de procedimentos como ouvir os dois lados, produz-se um simulacro de isenção. Utiliza-se a norma culta da língua e evitam-se as gírias e os palavrões (Ibid., p. 228).

Os sites selecionados para a nossa análise podem ser encaixados no que se chama imprensa séria, pois conservam as características próprias dessa modalidade.

\section{Procedimentos metodológicos}

Para atender à proposição deste trabalho, selecionamos seis notícias para análise, a qual respaldamos na teoria dos topoi argumentativos de Ducrot e Anscombre, no seu desenvolvimento com a Teoria dos Blocos Semânticos e em estratégias argumentativas estudadas pela Semântica Argumentativa.

Assim, em alguns momentos nos quais percebemos a força argumentativa de alguns termos, usamos a Teoria dos Blocos Semânticos (TBS), apresentada por Marion Carel em 1992. Na TBS, propõe-se a descrição das palavras, dos grupos de palavras e dos enunciados pelos discursos argumentativos que eles evocam, podendo comportar uma partícula consecutiva como "portanto" ou uma partícula opositiva como "no entanto". E a argumentação pode estar associada a uma palavra ou a uma expressão pela sua argumentação externa ou pela sua argumentação interna4. Dessa forma, associamos esses conceitos a algumas palavras e expressões usadas nos textos, concentrando-nos na descrição do sentido de algumas palavras e de alguns enunciados a partir de sua argumentação interna, a fim de verificar a qual posicionamento conduzem o leitor.

${ }^{4}$ Neste trabalho nossas AI foram redigidas na forma "X, portanto $Y$ " ou "X, no entanto $Y$ ”. 
EID\&A - Revista Eletrônica de Estudos Integrados em Discurso e Argumentação, llhéus, n. 11, jan/jun.2016.

Recorremos também à noção dos topoi argumentativos, por entendermos que cada teoria traz diferentes contribuições para nossa análise. Isso porque "[...] um predicado não faz referência apenas a uma propriedade do nome a que se liga, ele contém uma alusão a um 'lugar comum' (tópos) que autoriza algumas conclusões numa determinada comunidade" (CABRAL, 2011, p.53). Outros recursos argumentativos também foram mencionados.

A metodologia utilizada foi a qualitativa, porque não analisamos a frequência de termos ou operadores argumentativos, mas sim as direções argumentativas que percebíamos em cada notícia. Selecionamos seis notícias de quatro jornais diferentes a respeito de dois fatos distintos para análise. Isto é, frente a um tema, buscamos notícias nos jornais on-line do IG, da UOL e do Estadão, conforme anunciamos na introdução deste texto. Frente ao outro tema, recorremos aos mesmos jornais. A escolha por esses jornais se deu devido ao fato de que eles figuram entre os mais lidos pelos internautas, por atenderem ao ethos da imprensa séria e também por terem trazido, nos dias pesquisados, abordagens sobre um mesmo fato. A escolha dos dois temas deveu-se ao fato de serem temas atuais e terem gerado posicionamentos distintos.

O primeiro fato sobre o qual procuramos notícias em diferentes jornais eletrônicos foi o da aprovação da maioridade penal na Câmara dos Deputados e o segundo foi o da greve dos professores das universidades federais. Após a seleção das notícias, passamos à sua análise, cujos resultados apresentamos a seguir.

\section{Análise}

\subsection{Análise das notícias referentes à maioridade penal}

\subsubsection{Maioridade Penal - Notícia veiculada no site Uol, jornal Folha}

O primeiro texto em análise foi divulgado no site noticias.uol.com.br, na seção cotidiano. A notícia5 traz como manchete: "Sob protesto, comissão aprova reduzir a maioridade penal de 18 para 16 anos" (grifo nosso). Nesse texto, é possível perceber, já na manchete, a voz dos manifestantes, por meio da expressão "sob protesto". Pela organização sintática (deslocamento desse

5 Disponível em: http://noticias.uol.com.br/cotidiano/ultimas-noticias/2015/06/17/sob-protesto-eforte-seguranca-comissao-aprova-reducao-da-maioridade-penal.htm Acesso em: 01 jul.2015. 
EID\&A - Revista Eletrônica de Estudos Integrados em Discurso e Argumentação, Ilhéus, n. 11, jan/jun.2016.

adjunto adverbial para o início da frase), fica evidente a ênfase dada ao descontentamento dos manifestantes em relação à aprovação da Proposta.

No corpo desta notícia, encontramos expressões que corroboram a ideia de que os trabalhos na Câmara não ocorreram de forma tranquila, ou seja, não havia aprovação por parte de alguns segmentos sociais representados pelos manifestantes quanto aos trabalhos que ali se desenrolavam. Isso se comprova com o uso das expressões: (1) "Sob protestos", (2) "forte esquema de segurança", (3)" forte aparato de segurança", (4) "militantes de movimentos estudantis foram barrados" (grifos nossos). Valendo-nos da TBS, compreendemos a argumentação interna desses termos como: (1) "protestos" carrega na sua Al a ideia de "reclamação, portanto insatisfação"; (2) e (3) "esquema de segurança" e "aparato de segurança" trazem, na sua AI, a ideia de "medo, portanto medidas de precaução"; (4) a expressão "foram barrados" apresenta na sua Al "possibilidade de confronto, portanto medidas de segurança". Percebemos que as escolhas lexicais conduzem para a seguinte conclusão: o relatório foi aprovado, embora não tenha agradado a todos os segmentos sociais.

O uso da expressão "a PEC... deve ser votada" (grifo nosso) foi modalizada, apresentando a próxima etapa do processo como uma possibilidade. Ainda percebemos no trecho "após a votação, deputados da 'bancada da bala' provocaram os manifestantes cantando [...]", que a referência do locutor aos parlamentares se faz de forma pejorativa ("bancada da bala"). Usa-se, nesse caso, a argumentação pelo antimodelo, ou seja, um grupo que contém características que devem ser evitadas, segundo Fiorin (2015, p.190). Nesse caso, "bancada da bala" remete a parlamentares ligados à indústria de armas, ou seja, uma frente que defende interesses considerados politicamente incorretos. A atitude revelada por esses parlamentares de entoar a letra de uma música foi tomada como um ato de provocação.

Quanto aos hiperlinks sugeridos no corpo do texto, percebemos um direcionamento do leitor para a posição apresentada. O primeiro deles, "presidente Dilma Rousseff (PT) é contra a redução", direciona o leitor ao posicionamento assumido pela presidente, semelhante ao dos manifestantes, ou seja, contrário à redução da maioridade penal. Esse enunciador vem corroborar as ideias às quais se tem dado foco na notícia. O segundo hiperlink "acordo costurado pelo presidente da Câmara dos Deputados, Eduardo Cunha (PMDB-RJ)" faz uso da expressão “costurado" para designar o acordo selado 
EID\&A - Revista Eletrônica de Estudos Integrados em Discurso e Argumentação, Ilhéus, n. 11, jan/jun.2016.

entre partidos, o que traz uma carga semântica negativa de algo que precisou ser refeito e forçosamente unido, com o envolvimento de interesses vários. 0 terceiro hiperlink "o relatório pedia a redução da maioridade penal para todos os crimes" e o quarto "novo documento" conduzem à leitura do antigo e do novo documento, para que possam ser observadas as mudanças ocorridas no texto, em decorrência do acordo.

Na parte inferior da notícia são apresentados os seis vídeos que podem ser visualizados pelo leitor. Na íntegra, os conteúdos das chamadas são: (1) "Barrados na sessão, manifestantes fazem apitaço"; (2) "Relator da PEC diz que ouve voz das ruas; deputado rebate"; (3) "Deputada critica redução: "bala não resolve tudo"; (4) "Deputado critica manifestantes e defende redução"; (5) "Comissão da Câmara aprova redução da maioridade penal"; (6) "Deputados comemoram: 'sou brasileiro com muito orgulho"' (grifos nossos). Na seleção lexical feita para as chamadas, percebemos claramente em (1), (2), (3), (4), o intuito de polemizar, pelo uso das expressões "barrados na sessão" "apitaço", "voz das ruas", "rebate", "critica". Atentamos para o verbo critica (3) e (4), o qual traz na sua Al "não estar de acordo, portanto censurar"; essa escolha lexical vem corroborar o posicionamento do locutor do texto de que houve aprovação, mas ela não agradou a todos.

\subsubsection{Maioridade Penal - Notícia veiculada no Estadão}

O segundo texto em análise foi divulgado no site brasil.estadao.com.br, na seção geral, na mesma data em que as notícias anteriores, 17 de junho de 2015. A notícia ${ }^{6}$ aborda o mesmo tema encontrado nos outros jornais e traz como manchete "Comissão da Câmara aprova redução da maioridade penal". A manchete em si apenas relata o fato, de forma isenta e imparcial. No subtítulo, porém, já encontramos pistas do posicionamento adotado pelo locutor. No subtítulo "Com 21 votos a favor, comissão especial decidiu que serão punidos como adultos maiores de 16 anos que cometerem crimes graves", pela organização sintática, observa-se a ênfase dada à prevalência da opinião da maioria dos deputados ("com 21 votos a favor"). O número de votos foi apresentado em números absolutos: "21 votos favoráveis". Essa escolha na apresentação de números absolutos relativos à quantidade de votos se faz mais expressiva em relação ao número total de votos, que é 28.

6 Disponível em: http://brasil.estadao.com.br/noticias/geral,comissao-da-camara-aprova-reducaode-maioridade-penal,1708360 Acesso em: 01 jul.2015. 
EID\&A - Revista Eletrônica de Estudos Integrados em Discurso e Argumentação, Ilhéus, n. 11, jan/jun.2016.

Ou seja, 21 em 28 aparenta uma quantidade bastante expressiva. Já se a escolha pela apresentação do número de votos tivesse sido em porcentagem (77 por cento dos votos), poderia não ter o mesmo impacto numérico no leitor, não aparentaria uma quantidade muito expressiva. Recorre-se, portanto, ao lugar da quantidade de uma maneira específica para impressionar o leitor.

No corpo do texto, expressões usadas, tais como "manobra regimental do presidente da Câmara" e "acordo costurado" (grifos nossos), revelaram a ocorrência de conchavos para a aprovação da redução da maioridade penal. Esses conchavos, na crença geral aceita pela sociedade, não são considerados éticos. Essa conclusão implícita só é desvelada se observarmos que a seleção das palavras é que define os encadeamentos argumentativos, posição defendida por Cabral (2011, p. 53). Na mesma direção, é apresentado no subtítulo o termo "manobra", o qual assinala que houve aliança entre partidos para obtenção da maioria dos votos. Outro aspecto a ser observado foi o fato de a sessão ter sido tensa e ter dividido opiniões, o que se pode perceber pelo uso dos termos "pressionar"; "a sessão foi tensa"; "marcada por bate-boca entre parlamentares". Focando a Al de bate-boca: "divergência de opiniões, portanto contenda", percebemos que esse vocábulo, assim como os demais selecionados, orienta para o posicionamento adotado pelo locutor: a aprovação ocorreu pela maioria dos votos, porém dividiu opiniões.

Em uma seção denominada "Relacionadas", são apresentados três hiperlinks: (1) "Relator do projeto que reduz maioridade penal anuncia mudanças", (2)" "Bancada da bala' manobra para garantir votação da maioridade" e (3) "Governo articula no Senado proposta alternativa para não reduzir maioridade". Podemos observar a utilização de estratégias argumentativas presentes nas análises anteriores. Neste veículo, são usados os hiperlinks para atender ao simulacro da isenção, uma vez que apresenta posições de enunciadores distintos ("Relator", "Bancada da Bala" e “Governo"). Em (2), é usada a expressão "Bancada da bala” para desqualificar o grupo de deputados, como ocorreu também no site da Uol. E, reiterando as estratégias deste veículo, analisadas anteriormente, em (2) e (3), pelo uso dos termos "manobra" e "articula", temos a recorrência ao tópos de adesões resultantes de conchavos, ou seja, algo não considerado ético pela sociedade.

Os hiperlinks, além de sugerirem leituras complementares, parecem conduzir à reafirmação das ideias propostas no corpo da notícia. Além disso, 
EID\&A - Revista Eletrônica de Estudos Integrados em Discurso e Argumentação, Ilhéus, n. 11, jan/jun.2016.

funcionam como formadores de opinião, conduzindo o hiperleitor a assumir os pontos de vista desejados pelo jornal.

\subsubsection{Maioridade Penal - Notícia veiculada no site do iG}

O terceiro texto em análise, relativo ao fato 1 , foi divulgado no site ultimosegundo.ig.com.br, na seção Política. A notícia traz como manchete "Comissão aprova redução da maioridade penal para 16 anos". Tal qual no site anterior, a manchete em si apenas relata o fato, tentando dar ao fato um tratamento isento e imparcial.

O subtítulo "Relatório, que deve ser votado no Plenário, prevê imputabilidade para jovens em casos de crimes hediondos, homicídio doloso, lesão corporal grave, lesão corporal seguida de morte e roubo com causa de aumento de pena" (grifo nosso) também busca transmitir neutralidade, porém percebe-se que a ênfase do relator vai recair sobre o "relatório", o qual é apresentado com uma oração subordinada adjetiva explicativa na sequência (sublinhado), para apresentar maiores esclarecimentos sobre ele. $O$ relatório é retomado várias vezes no texto por meio das expressões "relatório do deputado", "texto do relator", "Proposta de Emenda à Constituição", "PEC", "o texto", expressões que denotam imparcialidade. No trecho em negrito, percebemos, porém, a ausência dos responsáveis pela votação, o que sugere uma desresponsabilização dos sujeitos envolvidos no processo. Os deputados não são citados, retirando deles o papel decisivo que assumem na votação do relatório.

No corpo da notícia, parece haver uma aprovação às medidas tomadas e aos procedimentos ocorridos para aprovação do relatório do deputado Laerte Bessa. São utilizadas as expressões "Bessa inicialmente pediria" e "recuou acolhendo sugestão" (grifos nossos). Recorrendo ao tópos evocado por "pedir" e "sugestão", concluímos que ambas as palavras denotam algo passível de ser aceito e não uma imposição ou algo resultante de conchavos ou outros procedimentos escusos. Por essa escolha, percebe-se uma não recriminação à forma como os trabalhos se encaminharam, diferentemente do que ocorre nos textos anteriores. Embora o locutor aponte que houve abuso por parte dos deputados defensores da redução da maioridade, o que para ele parece ter sido algo desnecessário, esse fato não ganhou relevância no texto.

7 Disponível em: http://ultimosegundo.ig.com.br/politica/2015-06-17/comissao-aprova-reducao-damaioridade-penal-para-16-anos.html. Acesso em: 01 jul.2015. 
EID\&A - Revista Eletrônica de Estudos Integrados em Discurso e Argumentação, Ilhéus, n. 11, jan/jun.2016.

Isso se evidencia no uso das expressões: "defensores da redução abusaram de sua força e ironizaram" e "O gesto foi uma forma de mostrar força". Na sequência, o locutor reforça as ideias aprovadas fazendo uso de um argumento de autoridade, a citação do artigo $5^{\circ}$ da Constituição Federal de 1988, inciso XLIII e ainda cita trechos do texto do relatório como forma de buscar objetividade.

Em seção intitulada "Leia mais", são apresentados dois hiperlinks: (1) "Sou discriminado, diz Bolsonaro ao aprovar $1^{\mathrm{a}}$ emenda em 25 anos de Congresso" e (2) "Com plenário fechado, comissão discute redução da maioridade penal”. Em (1), trata-se de um outro viés dado ao assunto, já que Bolsonaro foi um dos deputados favoráveis à redução da maioridade penal. Nessa chamada, dá-se voz a um sujeito político, que se inscreve como injustiçado. Seria uma "resposta" do deputado à polêmica que coloca, de um lado, os movimentos sociais e, de outros, os sujeitos políticos. Já em (2), tratase da mesma temática, porém de modo informativo, sem maiores posicionamentos sobre o tema. No corpo da notícia são sugeridos dois vídeos, um de Laerte Bessa, que é a favor da redução e o outro de Orlando Silva, que é contra. Como nas análises anteriores, percebemos a utilização do simulacro da isenção, uma vez que apresenta posições de enunciadores distintos sobre a temática abordada.

Ao final da notícia, sob o título "Veja também", é apresentado um link: "Deputados titulares da comissão da redução da maioridade penal". Por meio dele, o leitor tem acesso às fotos dos deputados que fazem parte da comissão e os partidos que a integram. Essa indicação parece valorizar os integrantes da comissão, ao mesmo tempo em que passa essa informação ao leitor.

\subsection{Análise das notícias referentes à greve das Universidades}

\subsubsection{Greve das Universidades - Notícia veiculada no site Uol, jornal Folha}

No jornal on-line Folha de São Paulo, a página de Educação trouxe a notícia 8 intitulada "Contra cortes, professores entram em greve em 19 universidades federais". Forma o lead dessa notícia: "Menos de uma semana após o governo Dilma Rousseff anunciar corte de $\mathrm{R} \$$ 9,4 bilhões na educação, professores de 19 universidades federais do país declararam nesta quinta-feira

Disponível em: http://www1.folha.uol.com.br/educacao/2015/05/1635102-contra-cortesprofessores-entram-em-greve-em-18-universidades-federais.shtml Acesso em: 25 jul.2015 
EID\&A - Revista Eletrônica de Estudos Integrados em Discurso e Argumentação, llhéus, n. 11, jan/jun.2016.

(28) greve por tempo indeterminado". Percebemos aí algumas escolhas lexicais que já apontam para o direcionamento argumentativo de que é a presidente quem está comprometendo a educação com os cortes que anunciou. A escolha da qualificação do governo como "governo Dilma Rousseff" já implica escolhas argumentativas, diferenciando-se de escolhas outras como "governo federal" que não marcariam tanto responsabilização do fato quanto pela nomeação da presidente.

O lead é escrito em ordem inversa, iniciando-se com um adjunto adverbial. Essa inversão dá ênfase à rapidez da decisão, intensificando a dificuldade de se manter um trabalho regular após um corte anunciado de tamanha proporção. Essa inviabilidade fica bem marcada no parágrafo que se segue ao lead, no trecho "a UFRJ chegou a fechar as portas neste mês". A expressão "chegou a" aumenta a força argumentativa, marca a extrapolação do limite do tolerável, funcionando como um modificador realizante junto à expressão "fechar as portas", reforçando o tópos negativo ligado a essa consequência da greve.

Relativamente à proporção do corte, a escolha pelo valor absoluto do corte de verba ( $R \$ 9,4$ bilhões) também é uma escolha argumentativa, visto que esse número absoluto traz mais impacto do que traria uma porcentagem, por exemplo, o que representaria apenas $13 \%$ do Orçamento da União. Neste caso, o número absoluto marca, argumentativamente, a importância que se atribui ao corte, marca da argumentação pelo "lugar da quantidade". A escolha da palavra "corte", palavra que aparece abrindo o parágrafo que segue ao lead, também reforça a direção argumentativa da notícia, visto que a utilização desse termo é mais enfática do que seriam termos como "redução de despesas", por exemplo. Este lead fica ainda marcado por uma argumentação do tipo "causa-consequência" visto que, logo de início, vem a marcação da causa (o corte orçamentário) para a consequência (greve docente) do corte.

Ainda contribui para a direção argumentativa o fato de que a greve declarada foi por "tempo indeterminado", sugerindo que possibilidades de acordo entre grevistas e governo estão distantes. Isso vem marcado no quarto e no quinto parágrafos da notícia que trazem, respectivamente, os trechos: "[...] que critica o governo [...] pela falta de negociação" e "[...] por acreditarem que a negociação como o governo federal ainda está no começo" (grifos nossos). 
EID\&A - Revista Eletrônica de Estudos Integrados em Discurso e Argumentação, Ilhéus, n. 11, jan/jun.2016.

Ainda marcam a direção argumentativa, no corpo da notícia, o hiperlink presente na palavra "comprometendo" que remete aos cortes em repasses às instituições federais. O hiperlink presente em "comprometendo" direcionanos a outra notícia do site intitulada "Greve nas universidades federais agrava crise após corte de verba". Sua objetividade frente ao fato veiculado apresenta-se no parágrafo 4, quando traz à tona opinião divergente de dois sindicatos de professores, o Andes (sindicato favorável à greve) e o Proifes (sindicato contrário à greve), configurando aí o simulacro da isenção.

Diferentemente de outras notícias, esta não dá voz ao governo, por ficar "diluída" na voz do sindicato Proifes. Os dois últimos parágrafos da notícia retomam a quantidade de locais atingidos pela greve e enfatizam que, além dos professores, funcionários de instituições federais também anunciaram paralisação. Por fim, a notícia relaciona uma lista de instituições federais em greve, marcando, também aqui, a argumentação pelo lugar da quantidade, ao enumerar de 1 a 19 o nome de cada instituição que aderiu ao movimento.

Na lateral desta notícia, há ainda três outros hiperlinks, em um espaço denominado "Leia também". Esses hiperlinks trazem os títulos de três outras notícias, sendo elas: (1) "Paradas, estaduais do PR suspendem seus vestibulares"; (2) "Greve nas universidades federais agrava crise após corte de verba" e (3) "Na dificuldade se vê valor das pessoas, diz ministro da Educação após cortes”. Em (1), a inversão da ordem direta da oração marca a greve com a forma nominal "paradas" e traz para o foco uma consequência negativa da paralisação, que é a suspensão de processos vestibulares. Em (2), a consequência negativa da greve também se apresenta com o agravamento de “crise após corte de verba", trazendo o pressuposto de que, mesmo antes do corte de verba, as universidades já estavam em crise financeira, pressuposto implícito no verbo "agrava”. Em (3), e apenas aí, é que aparece de forma explícita a opinião de quem está "do outro lado" nesta argumentação, opinião esta que é a do governo - que apareceu implícita, no corpo da notícia, no momento em que se trouxe, pelo discurso indireto, a voz do sindicato Proifes (contrário à greve).

Desse modo, mesmo sob a aparência da tentativa da imparcialidade, o espaço argumentativo que se dá aos grevistas e à falta de verbas para a educação é muito maior do que o espaço destinado à voz do governo, que poderia vir para defender a não necessidade da greve. 
EID\&A - Revista Eletrônica de Estudos Integrados em Discurso e Argumentação, Ilhéus, n. 11, jan/jun.2016.

\subsubsection{Greve das Universidades - Notícia veiculada no Estadão}

A notícia publicada no jornal Estadão (O Estado de S. Paulo) traz como título "Greve atinge 39 universidades federais". Nesse título, "a greve" é colocada como sujeito, diferentemente dos demais jornais, que trazem professores e funcionários como agentes do movimento.

Além de trazer o verbo "atingir", marcando a abrangência da greve, o título da notícia chama atenção, quando comparado aos dos demais jornais aqui analisados, pelo número que traz - 39-, o maior dentre os apresentados nas demais notícias. Neste caso, a ampliação é dada pelo verbo "atingir", visto que a greve "atingir" um número $x$ de universidades não significa que elas se encontrem paradas devido à greve. Pode-se inferir que ao menos um setor delas tenha sido afetado, mas não necessariamente as 39 universidades como um todo. Houve, então, argumentação pelo lugar da quantidade, dando foco ao número de universidades que trazem técnico-administrativos em greve.

O subtítulo dessa notícia apresenta as reivindicações dos grevistas e está bastante próximo ao apresentado na notícia do Último Segundo (iG) - análise apresentada a seguir -"Professores e funcionários pedem reposição de $27 \%$ de perdas salariais e revisão do contingenciamento de recursos às instituições". Todavia, no jornal Último Segundo a questão do corte de recursos aparece apenas no corpo do texto. No Estadão aparece no subtítulo, dando destaque, portanto, à questão dos cortes feitos na educação pelo governo federal. Em seguida, o lead reforça: "Com o corte de repasses do governo federal às universidades federais desde o início do ano e a falta de negociação sobre o reajuste salarial, professores e funcionários de 39 instituições decidiram, nesta quinta-feira, 28, pela greve". A causa da greve e a não negociação do governo aparecem no início do período, como adjunto adverbial deslocado, conferindo destaque a essas informações. Por aqui já percebemos o direcionamento argumentativo da notícia, que é o impacto governamental negativo junto às IES. Essa crítica aparece direcionada ao governo Dilma Rousseff (similar ao que ocorre na Folha).

Essa posição é perceptível no segundo parágrafo da notícia no trecho "[grevistas] pedem reposição de $27 \%$ de perdas salariais durante o governo Dilma Rousseff". Depois, traz a fala de um sindicato, na voz de Paulo Rizzo, como o faz o jornal Último Segundo, porém, com outro recorte de sua fala "O governo não negocia conosco, as federais vão fechar por inanição nos próximos meses se nada for feito". Esse recorte da fala de Paulo Rizzo corrobora a 
EID\&A - Revista Eletrônica de Estudos Integrados em Discurso e Argumentação, Ilhéus, n. 11, jan/jun.2016.

direção argumentativa da notícia. Para dar mais força ao dizer de Rizzo, a notícia aponta duas importantes universidades do país, a Unifesp e a UFSCar. Menciona que aquela apresenta \$7,5 milhões em dívidas - novamente argumentação pelo lugar da quantidade com o apontamento do valor absoluto da dívida - argumento com carga persuasiva bem marcada em seguida quando o jornal menciona que a paralisação afetará o Hospital São Paulo, visto que afetar a saúde parece ser mais do que afetar apenas a educação, mostrando a amplitude das consequências de uma greve em universidade. Quanto à UFSCar, a notícia menciona que até mesmo o restaurante universitário foi atingido, pois passará a servir as refeições apenas aos alunos bolsistas, isto é, vai atender apenas às necessidades mínimas dos estudantes bolsistas (alimentação).

O ideal de "imparcialidade" apresenta-se apenas idealizado no último parágrafo do texto. Nele, é colocado um trecho da nota do MEC frente à greve, recortando a mesma passagem apresentada pelo jornal último Segundo de que o MEC atende "tanto quanto pode, segundo realidades conjunturais, recursos disponíveis, agendas e acordos consagrados". Fica aí subentendida a opinião de que o governo muito pouco faz. Por outro lado, o espaço que se dá, argumentativamente e mesmo em número de parágrafos, para a voz do governo é bem menor, o que nos faz confirmar a direção argumentativa dessa notícia. Se formos aos hiperlinks para ver se a direção argumentativa se desfaz, percebemos que não.

Dos cinco hiperlinks que aparecem nessa notícia nenhum traz a visão do governo frente ao ato. Transcrevendo literalmente o conteúdo deles, temos: " 2 das 4 federais do Rio ficam de fora de greve nacional de professores", "Entidade de professores aprova indicativo de greve em 11 universidades federais"; "Servidores e mais de 4 Federais anunciam boicote ao Sisu"; "Duas universidades descumprem prazo de matrículas do Sisu" e "Unifesp e UFMG adiam rematrícula de alunos por causa da greve". Todos esses hiperlinks corroboram a ideia de que a greve gera um alto impacto social, reforçando a direção argumentativa de que greve é algo prejudicial para a população.

\subsubsection{Greve das Universidades - Notícia veiculada no site do iG}

O jornal on-line do site iG, denominado "Último Segundo", trouxe a notícia intitulada "Professores e técnicos de 18 das 59 universidades federais entram em 
EID\&A - Revista Eletrônica de Estudos Integrados em Discurso e Argumentação, Ilhéus, n. 11, jan/jun.2016.

greve"9. Essa notícia traz como subtítulo "Entre as reivindicações dos funcionários, estão reestruturação da carreira e reposição de $27 \%$ das perdas salariais". Aqui, a causa da greve é apresentada como sendo a reestruturação de carreira e a reposição de perdas. O lead dessa notícia é o seguinte: "Professores e trabalhadores técnico-administrativos de instituições públicas de ensino superior entram em greve nesta quinta (28) por tempo indeterminado, em vários estados. Os profissionais querem pressionar o governo federal a ampliar os investimentos na educação pública”. Diferentemente do que é apontado na notícia da Folha, o foco aqui não está no "corte", mas sim na necessidade de "ampliação de investimentos na educação".

Pelo título, pelo subtítulo e pelo lead, o leitor ainda não teve a informação dos cortes financeiros realizados junto às universidades, ou seja, ainda não se informou que a causa da greve foram os "cortes", como anunciou a notícia publicada na Folha, mas a falta de investimentos. A causa que se apresenta aqui, portanto, é diferente, em peso argumentativo, da realizada com a palavra "cortes" pelo outro jornal. É apenas no parágrafo seguinte que a notícia traz a informação dos cortes orçamentários anunciados pelo governo. Também o lead dessa notícia não direciona o problema ao "governo Dilma Rousseff", como a Folha faz, mas ao "governo federal", escolha semanticamente mais comedida, mais ligada ao princípio de "imparcialidade" do gênero.

No segundo parágrafo que compõe o corpo dessa notícia, são apresentados os números do corte orçamentário, trazidos aqui também com a utilização do número absoluto, mas apresentado com mais uma casa numérica no valor do que o anunciado na Folha: $\mathrm{R} \$ 9.423$ bilhões. Relativamente às solicitações dos grevistas, vem a explicação, no terceiro parágrafo, de que, entre as reivindicações, estão a reestruturação de carreira e reposição de $27 \%$ de perdas salariais. $E$, na sequência, vem a informação de que o último reajuste salarial feito fora em 2012. A apresentação de outras reivindicações, além do motivo da recusa ao corte realizado, aparece apenas neste jornal e no Estadão. Isso faz com que a greve pareça um pouco mais "justa", reforçando o tópos moral da necessidade da greve, visto que reajustes salariais são entendidos como necessários, discurso aceitável na sociedade.

9 Disponível em: http://ultimosegundo.ig.com.br/educacao/2015-05-28/professores-e-tecnicos-de-19das-59-universidades-federais-entram-em-greve.html Acesso em: 01 jul.2015 
EID\&A - Revista Eletrônica de Estudos Integrados em Discurso e Argumentação, Ilhéus, n. 11, jan/jun.2016.

Logo abaixo, o jornal dá voz ao presidente do Andes-SN (Paulo Rizzo), o qual alega que as universidades não estavam conseguindo nem mesmo "pagar as suas contas". Essa expressão remete a um fato além do limite do aceitável, visto que "pagar as suas contas" é o mínimo que cada instituição precisa conseguir. Essa utilização do disfemismo carrega uma força argumentativa expressiva, mas se apresenta no jornal na voz do outro. Após a fala de Paulo Rizzo, a notícia faz menção à greve dos técnico-administrativos e traz, também em discurso direto, protegendo a imagem do jornal, uma fala de seu representante - Fasubra. Segundo ele, as posições governamentais "não acatam a centralidade de nossas demandas", mostrando que não está havendo negociação.

Outros hiperlinks aparecem em seguida, abaixo do subtítulo. $O$ interessante é que para anunciar esses hiperlinks foi selecionado o termo "cortes", com maior carga argumentativa que outros antes utilizados. Essa escolha pode ser um recurso coesivo de não repetição de outros termos mais eufêmicos, mas acreditamos que chama mais a atenção aí, anunciando hiperlinks, do que se estivesse sendo utilizado no corpo do texto. Com isso, vemos que a notícia acaba apontando para um direcionamento argumentativo de que a greve ocorre porque o governo faz cortes na educação. E isso é reforçado nos hiperlinks sugeridos, que são: "Pronatec e Ciência sem Fronteiras sofrerão cortes este ano, diz MEC" e "Ministério das Cidades, Saúde e Educação lideram cortes no Orçamento". Aparece aí a voz de quem está do outro lado deste fato, que é a voz do governo. Todavia, o recorte da voz do governo é justamente um recorte de anúncio de outros cortes, corroborando para o direcionamento argumentativo que sugerimos haver.

\section{Considerações finais}

Após as análises das notícias selecionadas, podemos reafirmar o pressuposto do qual partimos, de que a imparcialidade no gênero textual notícia é um mito. Embora busquem transmitir os fatos da forma mais objetiva, imparcial e neutra, os locutores acabam desvelando suas posições perante o fato anunciado por meio da seleção lexical, das disposições gráficas, da hierarquização e das conexões estabelecidas no interior de um texto. No meio eletrônico, ainda são encontrados os hiperlinks, os quais consideramos como recurso adicional de que os locutores podem lançar mão para conduzir aos direcionamentos a que se propõem. 
EID\&A - Revista Eletrônica de Estudos Integrados em Discurso e Argumentação, Ilhéus, n. 11, jan/jun.2016.

Passamos aos nossos questionamentos, buscando responder a eles. Em resposta a "como o direcionamento nas notícias eletrônicas para uma conclusão ou perspectiva se faz?", percebemos que o direcionamento muitas vezes vem implicado nos elementos iniciais da notícia, seja no título, no subtítulo ou no lead por meio da presença de pressupostos, subentendidos ou escolhas lexicais de termos cujas Als apontam para um ou para outro direcionamento. Dessa forma e em resposta a "que contribuições o texto da notícia traz para o direcionamento?", notamos que o corpo da notícia é o que mais apresenta uma busca de imparcialidade, visto que geralmente há a preocupação em se dar voz aos diversos lados da questão em foco. Todavia, mesmo pelo espaço que se destina a dar voz a outros enunciadores, sugere-se um viés argumentativo. Esse viés vem bastante reforçado nos hiperlinks, os quais (e já respondendo à terceira pergunta) reforçam o direcionamento sugerido no decorrer do texto. Por fim, notamos que o direcionamento argumentativo se faz presente desde o início do texto (em suas sessões iniciais) e se confirma tanto no texto base, quanto (e sobretudo) nos hiperlinks, visto que o hiperleitor é conduzido por caminhos previamente selecionados pelo locutor da notícia.

Reafirmamos, assim, a ideia de que todo texto, inclusive as notícias, estão carregadas de ideologias e podem conduzir o leitor a determinados posicionamentos. A isenção de opiniões no gênero "notícia" veiculado em jornais on-line, alvo de nossa pesquisa, é apenas um simulacro, uma forma de representação, como ocorre nos jornais impressos. Além das pistas observadas nos elementos constitutivos do gênero notícia, os hiperlinks apresentados em cada uma delas constituem recursos relevantes e contribuem, de forma significativa, para direções argumentativas pretendidas pelo locutor do texto.

Por ser o jornal virtual acessado por um grande número de leitores, entendemos que são relevantes mais trabalhos que pesquisem os direcionamentos argumentativos sugeridos por esse meio de comunicação. Analisamos os elementos verbais presentes nas notícias on-line bem como os hiperlinks apresentados. É interessante que outras pesquisas sejam feitas observando até mesmo os elementos não verbais presentes no gênero, considerando imagens selecionadas, ângulo escolhido para imagens, utilização de cores e de tamanho de fontes utilizadas, bem como destaques e grifos no texto. Enfim, há muito ainda a explorar no gênero textual "notícia on-line", uma vez que o momento histórico em que vivemos exige dos leitores uma visão crítica e mais profunda daquilo a que estão expostos e, como 
EID\&A - Revista Eletrônica de Estudos Integrados em Discurso e Argumentação, Ilhéus, n. 11, jan/jun.2016.

constatamos, nem mesmo as notícias têm caráter imparcial, sugerindo direcionamentos argumentativos pretendidos por um locutor. Por trás de escolhas feitas, há posicionamentos argumentativos a serem desvelados.

\section{Referências}

CABRAL, Ana Lúcia Tinoco. A força das palavras: dizer e argumentar. São Paulo: Contexto, 2010.

CAREL, Marion. Argumentation interne et argumentation externe au lexique des propriétés différentes. Languages 142, jun/2001, p.10-21.

DUCROT, Oswald. Provar e dizer: leis lógicas e leis argumentativas. São Paulo: Global Ed., 1981.

. Argumentação e "topoi" argumentativos In: GUIMARÃES, Eduardo (Org.) História e sentido na linguagem. Campinas: Pontes, 1989. p.13-38.

FIORIN, José Luiz. Argumentação. São Paulo: Contexto, 2015.

FIORIN, José Luiz; SAVIOLI, Francisco Platão. Licões de texto: leitura e redação. São Paulo: Ática, 1996.

MARTINS, Eduardo. Manual de Redação e Estilo de 0 Estado de S. Paulo. $3^{\text {a }}$ edição, revista e ampliada. São Paulo: O Estado de S. Paulo, 1997.

MOSCA, Lineide do Lago Salvador. Velhas e novas retóricas: convergência e desdobramentos. In: MOSCA, Lineide do Lago Salvador (Org.) Retóricas de ontem e de hoje. São Paulo: Humanitas, 1999.

RAMOS, José Nabantino. Jornalismo: Dicionário Enciclopédico. São Paulo: Ibrasa, 1970.

ROSSI, Michelle; MARQUES RAMIRES, Mário. A Imparcialidade como Conceito de Qualidade Jornalística. Comunicação \& Mercado, Dourados, v. 1, n. 04, p. 77-83, jan-jul 2013. Disponível em: <http://www.unigran.br/mercado/paginas/arquivos/edicoes/4/7.pdf>. Acesso em: 21.jul.2015.

Forma de citação sugerida:

GOMES, Lívia Letícia Zanier; RABELO, Bárbara Helena. Direcionamento argumentativo em notícias on-line. EID\&A - Revista Eletrônica de Estudos Integrados em Discurso e Argumentação, Ilhéus, n. 11, p. 36-54, jan/jun.2016.

Recebido em: 26/11/2015

Aprovado em: 11/05/2016 